pfindlichkeit hat der Verfasser in der Art Versuche angestellt, dass er 2 cc einer Lösung der Phenole in Chloroform im Verhältniss 1:1000 mit einem Stückchen Aetzkali im Reagircylinder kochte und dann bis $z u$ der Grenze der Sichtbarkeit verdünnte. Carbolsäure lieferte eine blassrothe Färbung bis zur Verdünnung 1:60000. Ortho-Kresol lilaroth bis 1:80000, Meta-Kresol mehr orangeroth, gleich empfindlich. Thymol prachtvoll purpurroth mit einem Stich in's Violette bis $1: 20000$. Guajacol kirschroth mit einem Stich in's Blaue, geht in violettblau uber, bis $1: 100000$, Resorcin bis 1:500000, Beta-Naphtol berlinerblau, geht in grün und braun uber bis 1:80000. Salol erzengt eine Färbung wie Carbolsäure, Betol eine solche wie Naphtol. Im Allgemeinen gibt Aetzkali intensivere Färbungen als Aetznatron. Alkohol und Aether verhindern in manchen Fällen die Reaction. Zam Nachweis der Phenole neben anderen Körpern (in Speisebrei, Arzneimitteln, Blut, Urin) empfiehlt der Verfasser mit verdünnter Schwefelsäure anzusäuern und mit Wasserdämpfen zu destilliren. Schon die ersten übergehenden Tropfen enthalten meist das Phenol; man schüttelt es in einem Scheidetrichter mit $5 c c$ Chloroform aus, trennt letzteres von der wässerigen Flüssigkeit und erwärmt mit einem Stückchen Kalihydrat. Enthält die Flüssigkeit Alkohol, so macht man sie erst alkalisch, destillirt den 'Alkohol ab, säuert dann an und verfährt wie oben angegeben. Die Reaction lässt sich auch zum Nachweise von Chloroform, Chloral oder Jodoform benutzen. Man wählt als Phenol dazu am besten das $\beta$-Naphtol, welches eine blaue Färbung gibt.

\title{
Zur Unterscheidung des Resorcins von Carbolsäure und Salicyl-
} säure benutzt $\mathrm{H} . \mathrm{B}$ od d $\mathrm{e}^{*}$ ) das Verhalten za unterchlorigsaurem Natron. Bringt man einige Tropfen einer Lösung des letzteren Körpers zu einer wässerigen oder alkoholischen Resorcinlösung, so entsteht eine violette, rasch in gelb übergehende Fürbung. Erwärmt man, oder setzt man einen Ueberschuss von unterchlorigsaurem Natron zu, so wird die Flüssigkeit dunkelbrawn. Die Reaction tritt selbst noch bei einer Verdünnung der Resoreinlösung von 1:10000 ein. Carbolsäure, Salicylsäure und Benzoësäure zeigen die Reaction nicht, beim Erwärmen tritt nur eine schwach gelbe Färbung auf. Pyrocatechin gibt mit dem Reagens eine bald verbleichende, grüne Färbung, Hydrochinon wird bald gelb und roth.

*) Nederl. Tijdschr. v. Pharm. Mai 1889; durch The Analyst 14, 115. 
Versetzt man die Flüssigkeit erst mit etwas Ammoniak und dann mit einigen Tropfen unterchlorigsauren Natrons, so erhält man bei Anwesenheit von Resorcin eine rothviolette Färbung, die beim Kochen in grün übergeht. Die färbende Substanz wird nicht von Benzol aufgenommen. Salicylsäure, Benzoësäure oder Acetanilid geben die Reaction nicht. Carbolsäure liefert, in dieser Weise behandelt, eine grünblaue Färbung, die durch Benzol theilweise zerstört wird. Durch Zusatz vonverdünnter Schwefelsäure tritt bei den zuletzt erwähnten Farbenreactionen Umschlag in Roth ein.

L. van Itallie*) schlägt vor, zur Unterscheidung von Phenol und Resorcin von Salicylsäure das verschiedene Verhalten der durch Eisenchlorid hervorgerufenen Färbung zu Milchsäure zu benutzen.

Wenn man zu 100 cc einer 2 procentigen Phenol- oder Resorcin-, oder zu einer gesättigten Salicylsäurelösung 2 Tropfen Eisenchloridlösung setzt, so erhält man bekanntlich eine blauviolette Fürbung. Auf Zusatz eines Tropfens Milchsäure geht dieselbe bei Phenol und Resorcin in eine gelbgrüne über, während die Salicylsäurefärbung durch einen Zusatz von 10 Tropfen Milchsäure nicht verschwindet.

Ueber die Farbenreactionen und die Aldehydnatur der Holzfaser hat F. Nicke $1^{* *}$ ) Mittheilungen gemacht, auf welche ich hier im Anschluss an die frühere Arbeit des Verfassers ${ }^{* * *}$ ) nur hinweisen kann, da es bei denselben sich weniger um neve Reactionen, als vielmehr um die theoretische Deutung der verschiedenen bekannten Ligninreactionen handelt.

Ueber den Nachweis des Saccharins (Benzoësäuresulfinids) hat B. Haas $\dagger$ ) seine Erfahrungen mitgetheilt. Da er die von Börnstein †) angegebene Fluorescenzreaction bei einer Anzahl von Süssweinen erhielt, welche, nach dem Verfahren von C. Schmittht†) geprüft, keine Salicylsäure lieferten, so stellte der Verfasser unter genauer Einhaltung der von Börnstein gegebenen Vorschriften Versuche mit Resorcin, Weinsäure, Aepfelsäure, Bernsteinsäure, Citronensäure und Rohrzucker an und

*) Apotheker-Zeitung 4, 99; durch Chemiker-Zeitung 13, R. 47.

**) Botanisches Centralblatt 1889, Nr. 23; vom Verfasser eingesandt.

***) Vergl. diese Zeitschrift 28, 244.

†) Zeitschrift für Nahrungsmittel-Untersuchnug und Hygiene 3, 53; durch Chemikerzeitung 13, 96 und Deutsche Chemikerzeitung 4, 116.

t†) Diese Zeitschrift 27, 165 und 28, 352.

†††) Vergl. diese Zeitschrift 27, 396. 